Mössbauer Spectroscopy as a Probe of Electric Field in Heme Pocket of Deoxyheme Proteins: Theoretical Approach

Alexandr Gorski ${ }^{1}$, Aleksandr Starukhin ${ }^{2}$, and Solomon S. Stavrov, ${ }^{3, *}$

${ }^{1}$ Institute of Physical Chemistry, Polish Academy of Sciences, Kasprzaka, 44/52, 01-224 Warsaw, Poland,

${ }^{2}$ B.I. Stepanov Institute of Physics, National Academy of Science of Belarus, Nezalezhnasti Ave., 70, 220072 Minsk, Belarus

${ }^{3}$ Sackler Institute of Molecular Medicine, Department of Human Molecular Genetics and

Biochemistry, Sackler School of Medicine, Tel Aviv University, Tel Aviv 69978, Israel.

J Radioanal Nucl Chem (2017) 313:141-144

DOI 10.1007/s10967-017-5294-y

This project has received funding from the European Union's Horizon 2020 research and innovation programme under the Marie Skłodowska-Curie grant agreement No. 645628

Project Number: 645628

Project Acronym: METCOPH

Project title: Metallocomplexes of macrocyclic compounds

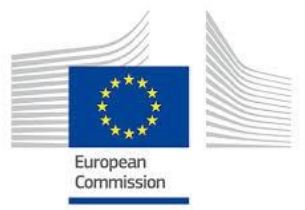




\title{
Mössbauer Spectroscopy as a Probe of Electric Field in Heme Pocket of Deoxyheme Proteins: Theoretical Approach
}

\author{
Alexandr Gorski ${ }^{1}$, Aleksandr Starukhin ${ }^{2}$, and Solomon S. Stavrov, ${ }^{3 *}$ \\ ${ }^{1}$ Institute of Physical Chemistry, Polish Academy of Sciences, Kasprzaka, 44/52, 01-224 Warsaw, \\ Poland, \\ ${ }^{2}$ B.I. Stepanov Institute of Physics, National Academy of Science of Belarus, Nezalezhnasti Ave., 70, \\ 220072 Minsk, Belarus \\ ${ }^{3}$ Sackler Institute of Molecular Medicine, Department of Human Molecular Genetics and \\ Biochemistry, Sackler School of Medicine, Tel Aviv University, Tel Aviv 69978, Israel.
}

\begin{abstract}
Chemical reactions taking place in active centers of different enzymes are controlled by electric fields created by the protein in these centers. These electric fields can be experimentally detected by different experimental techniques (infrared absorption, NMR, etc.). In this paper, we use quantum chemical calculations to show that Mössbauer spectroscopy can be also used to study protein electric field. We study effect of both the model and protein electric fields on the magnitude of quadrupole splitting of Mössbauer spectra of the high-spin ferrous myoglobin and its models. It is shown that the quadrupole splitting is notably affected by the protein electric field. This result also explains a number of the experimental data.
\end{abstract}

\section{Keywords}

heme proteins; myoglobin; hemoglobin; protein dynamics; porphyrin. 


\section{Introduction}

.Relationship between structure, dynamics and function of enzymes is one of the major problems of modern biochemistry and biophysics. It is clear that environment of the active center of an enzyme creates an electric field (EF), the latter affecting chemical reactions taking place in the active center (see, for example [1]). Therefore, it is very important to study this EF and its spatial distribution.

Heme proteins (HPs) are widely used to address this problem, because they can be studied by optical and infrared absorption, NMR, Raman scattering and many other experimental techniques. The effect of the heme environment on the electronic structure, spectra and properties of the heme active center have been studied both experimentally (for reviews see [2-7]) and theoretically using the vibronic theory of activation [8-13] and direct quantum chemical calculations.[14-18,3,19,20] It was shown that in carbon monoxide complex of myoglobin $(\mathrm{MbCO})$ the electronic structure and, consequently, the spectra $\left({ }^{13} \mathrm{C}\right.$, and ${ }^{17} \mathrm{O}$ nuclear magnetic resonance spectra, optical absorption and infrared absorption spectra) are notably affected by the heme environment EF. Comparison of the experimentally observed $\mathrm{C}-\mathrm{O}$ vibrational frequency, $\mathrm{v}(\mathrm{CO})$, and the dissociation rate constants of $\mathrm{CO}$, $\mathrm{NO}$ and $\mathrm{O}_{2}$ of different $\mathrm{Mb}$ mutants with the calculated $\mathrm{EF}$ in the heme pocket showed [4] that the protein EF affects both the $v(\mathrm{CO})$ and the affinity of the heme for these diatomic ligands. A recent study of the $\mathrm{CO}$ complex of horseradish peroxidase showed that not only the position of the $\mathrm{CO}$ infrared band, but also its width is very revealing, providing specific information on the dynamics of the heme environment (see, for example [21-24]).

The quadrupole splitting $\left(\Delta \mathrm{E}_{\mathrm{Q}}\right)$ of the excited nuclear state of iron isotope ${ }^{57} \mathrm{Fe}$ is observed in Mössbauer spectra [25-32] and provides one with direct information about the inhomogeneity of the electric field (electric field gradient, EFG), produced on the iron nucleus by its environment, both the electron cloud and external electric field. $\Delta \mathrm{E}_{\mathrm{Q}} \mathrm{S}$ of HPs and iron porphyrin complexes were extensively studied theoretically.[15,16,33,34] These studies showed that application of the DFT approach produces good results on computations of $\Delta \mathrm{E}_{\mathrm{Q}} \mathrm{s}$. 
Effect of the protein EF on $\Delta \mathrm{E}_{\mathrm{Q}}$ of only closed-shell HPs with big energy gap between the excited states and the ground one was studied earlier; it was shown to be very weak.[16] This result is well understood, because admixture of the excited states to the ground one by external perturbations is weak and, consequently, distribution of electronic cloud around the iron nucleus in such compounds is weakly affected by the perturbations.

At the same time in HPs containing open-shell iron its electronic structure is expected to be much more sensitive to any perturbations (including EF) than that of closed-shell heme proteins, because the energy gap under consideration is much smaller. However, to our best knowledge effect of external EFs on $\Delta \mathrm{E}_{\mathrm{Q}}$ of these compounds was not studied theoretically.

In this letter we report results of theoretical study of effects of different model EFs on $\Delta \mathrm{E}_{\mathrm{Q}}$ of the highspin $(\mathrm{S}=2)$ iron-porphin-imidazole complex $(\mathrm{Fe}(\mathrm{P})(\mathrm{Im}))$, model of the $\mathrm{Mb}$ active center, and of $\mathrm{EF}$ of the distal environment of the heme on $\Delta \mathrm{E}_{\mathrm{Q}}$ of myoglobin.

\section{Theory}

$\Delta \mathrm{E}_{\mathrm{Q}}$ of the iron atom is controlled by the principal components of the EF gradient tensor $\left(V_{z z}, V_{y y}\right.$, and $\left.V_{x x},\left|V_{z z}\right|>\left|V_{y y}\right|>\left|V_{x x}\right|\right)$ on this atom.

$$
\Delta E_{Q}=\frac{1}{2} e Q V_{z z}\left(1+\frac{\eta^{2}}{3}\right)^{\frac{1}{2}},
$$

where

$$
\eta=\frac{V_{x x}-V_{y y}}{V_{z z}},
$$

$e$ is the electron charge and $Q=0.16 \cdot 10^{-28} \cdot \mathrm{m}^{2}$ is quadrupole moment of the ${ }^{57} \mathrm{Fe} \mathrm{I}^{*}=3 / 2$ excited state.[15] 
To check how different model EFs and the EF of the closest heme environment affect $\Delta \mathrm{E}_{\mathrm{Q}}$, we computed $V_{z z}, V_{y y}$, and $V_{x x}$ using the DFT approach utilizing pure functional BPW91 (Becke 88 exchange and PW91 correlation functionals); spin unrestricted method; and Wachter's all electron basis set for iron, 6-311G* set for other heavy atoms, and 6-31G* set for hydrogen atoms [15], as it was implemented in the Gaussian 03 package [35]. Note, that this approach was shown to reliably calculate $\Delta \mathrm{E}_{\mathrm{Q}}$ of isolated active centers of different closed- and open-shell HPs.[15]

\section{Results and Discussion}

In the beginning, the geometry optimization of the high-spin $\mathrm{Fe}(\mathrm{P})(\mathrm{Im})$ complex was performed. Then the electronic structures of $\mathrm{Fe}(\mathrm{P})(\mathrm{Im})$ in the presence of $\mathrm{E}=0.01$ a.u. homogeneous $\mathrm{EFs}(1$ a.u. $=$ $5.14 \cdot 10^{9} \mathrm{~V} / \mathrm{cm}$, this magnitude of the field being of the order of the field in the heme pocket $\left.[4,36]\right)$

directed parallel $\left(\mathrm{E}^{\|}\right)$and perpendicular $\left(\mathrm{E}^{\perp}\right)$ to the porphyrin plane, were calculated. Effects of changes in the iron out of the porphyrin plane displacement (r) and distance between the iron and nitrogen of the proximal imidazole $(\mathrm{R})$ were also studied.

The geometry optimization of the high-spin $\mathrm{Fe}(\mathrm{P})(\mathrm{Im})$ complex yielded $\mathrm{r}=0.32 \AA$ and $\mathrm{R}=2.12 \AA$.

To understand how strong the EF effect is, one has to compare this effect to the one of the heme distortions. To do that we calculated the effect of two widely discussed and functionally important heme distortions: changes in $\mathrm{r}$ and $\mathrm{R}$ to $0.42 \AA$ (note that in hemoglobin $\mathrm{r} \approx 0.4 \AA$ [37]) and $2.27 \AA$, respectively. Note, that elongation of the covalent iron-imidazole bond R by $0.15 \AA$ substantially affects the electron cloud around the iron atom.

The results are presented in Table 1 . They show that both the distortions and EFs affect $\Delta \mathrm{E}_{\mathrm{Q}}$, the perpendicular to the porphyrin plane $\mathrm{EF}$ affecting $\Delta \mathrm{E}_{\mathrm{Q}}$ not less, than the distortions under consideration. The field parallel to the porphyrin plane hardly changes $\Delta \mathrm{E}_{\mathrm{Q}}$. Note, that homogeneous $\mathrm{EF}$ by itself does not affect $\Delta \mathrm{E}_{\mathrm{Q}}$. Consequently, the change in $\Delta \mathrm{E}_{\mathrm{Q}}$ reflects the reorganization of electron cloud around the iron nucleus caused by the homogeneous EF. 
Table 1 Influence of the distortions and of the homogeneous $\mathrm{EF}$ on $\Delta \mathrm{E}_{\mathrm{Q}}$ of the high-spin $\mathrm{Fe}(\mathrm{P})(\mathrm{Im})$

\begin{tabular}{|c|c|c|}
\hline & $\Delta \mathrm{E}_{\mathrm{Q}} \mathrm{mm} / \mathrm{s}$ & $\eta$ \\
\hline $\begin{array}{c}\mathrm{r}=0.32 \AA, \mathrm{R}=2.12 \AA \\
\mathrm{E}=0\end{array}$ & -2.06 & 0.77 \\
\hline $\begin{array}{c}\mathrm{r}=0.42 \AA, \mathrm{R}=2.12 \AA \\
\mathrm{E}=0\end{array}$ & -2.13 & 0.97 \\
\hline $\begin{array}{c}\mathrm{r}=0.32 \AA, \mathrm{R}=2.27 \AA \\
\mathrm{E}=0\end{array}$ & -2.18 & 0.48 \\
\hline $\begin{array}{c}\mathrm{r}=0.32 \AA, \mathrm{R}=2.12 \AA \\
\mathrm{E}^{\|}=0.01 \text { a. u. }\end{array}$ & -2.06 & 0.76 \\
\hline $\begin{array}{c}\mathrm{r}=0.32 \AA, \mathrm{R}=2.12 \AA \\
\mathrm{E}^{\perp}=0.01 \text { a. u. }\end{array}$ & -1.94 & 0.91 \\
\hline $\begin{array}{c}\mathrm{r}=0.32 \AA, \mathrm{R}=2.12 \AA, \\
\mathrm{E}^{\perp}=-0.01 \text { a. u. }\end{array}$ & -2.11 & 0.64 \\
\hline
\end{tabular}

The effect of the closest heme environment on $\Delta \mathrm{E}_{\mathrm{Q}}$ of $\mathrm{Mb}$ was also computed. To do this we used the X-ray data [38]. We simulated the distal and proximal histidines with imidazoles and neglected the contribution of the peripheral porphyrin residues. The latter assumption is based on (a) the fact that these residues do not participate in the porphyrin pi-conjugation, and (b) our finding that EF parallel to the porphyrin plane hardly affects $\Delta \mathrm{E}_{\mathrm{Q}}$, see Table 1 . The relative positions of heavy atoms of the 
heme, distal imidazole, and hydrogen bonded water molecule were taken from [38], then the hydrogen atoms were added and their positions were refined by the geometry optimization using the same quantum chemical approach, see Fig. 1.

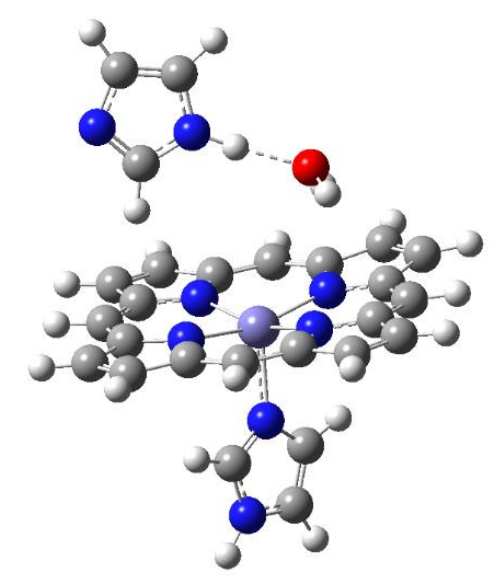

Fig. 1 Structure of heme and its distal environment in myoglobin [38] with optimized positions of the hydrogen atoms ( $\mathrm{Fe}$ - violet, $\mathrm{O}$ - red, $\mathrm{N}$ - blue, $\mathrm{C}$ - grey, $\mathrm{H}$ - white)

Using this structure, we computed $\Delta \mathrm{E}_{\mathrm{Q}}$ of the heme-imidazole complex with and without the distal environment, the results being presented in Table 2.

Table 2 Influence of $\mathrm{EF}$ of the distal imidazole and the water molecule on $\Delta \mathrm{E}_{\mathrm{Q}}$ of myoglobin heme

\begin{tabular}{|c|c|c|}
\hline & $\Delta \mathrm{E}_{\mathrm{Q}}, \mathrm{mm} / \mathrm{s}$ & $\eta$ \\
\hline Heme & -2.08 & 0.68 \\
\hline Heme and distal & -2.18 & 0.69 \\
environment & & \\
\hline
\end{tabular}


It follows from Table 2 that $\mathrm{EF}$ of the distal environment, histidine and water changes $\Delta \mathrm{E}_{\mathrm{Q}}$ by 0.1 $\mathrm{mm} / \mathrm{s}$, this change being just a beat weaker, than the effect of the elongation of the covalent ironimidazole bond by $0.15 \AA, 0.12 \mathrm{~mm} / \mathrm{s}$, see Table 1 . It follows from this comparison, that the protein EF can affect $\Delta \mathrm{E}_{\mathrm{Q}}$ of deoxyheme proteins to the same extent as relatively large heme structural changes. Consequently, the protein EF effect is notable and measurable and has to be taken into account when interpreting Mossbauer spectra of these proteins.

Note, that taking into account the EF of the heme environment improves the theoretical result, making it considerably closer to the experimentally observed value of $-2.22 \mathrm{~mm} / \mathrm{s}$ [39], but hardly affects $\eta$.

It follows from the results presented above that both the model and protein electric fields notably affect the quadrupole splitting of the ferrous iron of $\mathrm{Fe}(\mathrm{P})(\mathrm{Im})$ and of ferrous deoxyheme proteins.

To our best knowledge, the results presented in this letter are the first demonstration of the effect of an external $\mathrm{EF}$ on $\Delta \mathrm{E}_{\mathrm{Q}}$. It stems from the re-organization of the electronic cloud around the iron nucleus caused by the EF.

This effect of the protein EF can explain, at least partially, the deviation between the experimental results and those, obtained without taking into account the EF.[15] It also can contribute to the broadening of the deoxyhemoglobin Mössbauer spectra [30] as a result of different heme environment in $\alpha$ and $\beta$ subunits of hemoglobin.[37]

\section{Conclusion}

It follows from the results presented above that external electric field can notably affect quadrupole splitting of complexes with open-shell metal atoms. As such, on the one hand, it must be taken into account when interpreting the experimental data. On the other hand, it can be used as an effective probe of external electric fields, including protein electric field.

\section{Acknowledgements}


The authors are very much grateful to financial support by the European Framework Programme for Research and Innovation Horizon 2020, Grant Agreement No: 645628 - METCOPH - H2020MSCA-RISE-2014.

\section{References}

1. Lai WZ, Chen H, Cho KB, Shaik S (2010) External Electric Field Can Control the Catalytic Cycle of Cytochrome P450(cam): A QM/MM Study. J Phys Chem Lett 1 (14):2082-2087.

2. Park KD, Guo K, Adebodun F, Chiu ML, Sligar SG, Oldfield E (1991) Distal and proximal ligand interactions in heme proteins: correlations between $\mathrm{C}-\mathrm{O}$ and $\mathrm{Fe}-\mathrm{C}$ vibrational frequencies, oxygen-17 and carbon-13 nuclear magnetic resonance. Biochemistry 30:2333-2347.

3. Spiro TG, Zgierski MZ, Kozlowski PM (2001) Stereoelectronic factors in CO, NO and O-2 binding to heme from vibrational spectroscopy and DFT analysis. Coord Chem Rev 219:923-936.

4. Phillips GN, Teodoro ML, Li TS, Smith B, Olson JS (1999) Bound CO is a molecular probe of electrostatic potential in the distal pocket of myoglobin. J Phy Chem B 103 (42):8817-8829.

5. Goldbeck RA, Pillsbury ML, Jensen RA, Mendoza JL, Nguyen RL, Olson JS, Soman J, Kliger DS, Esquerra RM (2009) Optical Detection of Disordered Water within a Protein Cavity. Journal of the American Chemical Society 131 (34):12265-12272.

6. Esquerra RM, Jensen RA, Bhaskaran S, Pillsbury ML, Mendoza JL, Lintner BW, Kliger DS, Goldbeck RA (2008) The $\mathrm{pH}$ dependence of heme pocket hydration and ligand rebinding kinetics in photodissociated carbonmonoxymyoglobin. Journal of Biological Chemistry 283 (20):14165-14175.

7. Muller JD, McMahon BH, Chien EYT, Sligar SG, Nienhaus GU (1999) Connection between the taxonomic substates and protonation of histidines 64 and 97 in carbonmonoxy myoglobin. Biophysical Journal 77 (2):1036-1051.

8. Stavrov SS, Decusar IP, Bersuker IB (1993) Chemical activation of oxygen and carbon-monoxide by hemoproteins - the vibronic approach. New J Chem 17 (1-2):71-76.

9. Bersuker IB (1978) Mutual Vibronic Influence of Weakly Coordinated Molecular Systems in Chemical-Reactions and Catalysis. Chemical Physics 31 (1):85-93. 
10. Kushkuley B, Stavrov SS (1996) Theoretical study of the distal-side steric and electrostatic effects on the vibrational characteristics of the $\mathrm{FeCO}$ unit of the carbonylheme proteins and their models. Biophysical Journal 70 (3):1214-1229.

11. Kushkuley B, Stavrov SS (1997) Theoretical study of the electrostatic and steric effects on the spectroscopic characteristics of the metal-ligand unit of heme proteins. 2. C-O vibrational frequencies, O-17 isotropic chemical shifts, and nuclear quadrupole coupling constants. Biophysical Journal 72 (2):899-912.

12. Stavrov SS (2008) The FeCO unit vibrations as a probe of the structure and dynamics of the active site of heme proteins: combined quantum chemical, vibronic and spectroscopic study. In: Németh TS (ed) Biopolymer Research Trends. Nova Publishers, pp 119-143.

13. Daskalakis V, Varotsis C (2009) Binding and Docking Interactions of NO, CO and O-2 in Heme Proteins as Probed by Density Functional Theory. Int J Mol Sci 10 (9):4137-4156.

14. Oldfield E, Guo K, Augspurger JD, Dykstra CE (1991) A molecular model for the major conformational substates in heme proteins. Journal of the American Chemical Society 113:7537-7541. 15. Zhang Y, Mao JH, Godbout N, Oldfield E (2002) Mossbauer quadrupole splittings and electronic structure in heme proteins and model systems: A density functional theory investigation. Journal of the American Chemical Society 124 (46):13921-13930.

16. McMahon MT, deDios AC, Godbout N, Salzmann R, Laws DD, Le HB, Havlin RH, Oldfield E (1998) An experimental and quantum chemical investigation of CO binding to heme proteins and model systems: A unified model based on $\mathrm{C}-13$, O-17, and Fe-57 nuclear magnetic resonance and $\mathrm{Fe}-$ 57 Mossbauer and infrared spectroscopies. Journal of the American Chemical Society 120 (19):47844797.

17. Havlin RH, Godbout N, Salzmann R, Wojdelski M, Arnold W, Schulz CE, Oldfield E (1998) An experimental and density functional theoretical investigation of iron-57 Mossbauer quadrupole splittings in organometallic and heme-model compounds: Applications to carbonmonoxy-heme protein structure. Journal of the American Chemical Society 120 (13):3144-3151.

18. Ghosh A, Bocian DF (1996) Carbonyl tilting and bending potential energy surface of carbon monoxyhemes. Journal of Physical Chemistry 100 (16):6363-6367. 
19. Franzen S (2001) Effect of a charge relay on the vibrational frequencies of carbonmonoxy iron porphine adducts: The coupling of changes in axial ligand bond strength and porphine core size. Journal of the American Chemical Society 123 (50):12578-12589.

20. Franzen S (2002) An electrostatic model for the frequency shifts in the carbonmonoxy stretching band of myoglobin: Correlation of hydrogen bonding and the Stark tuning rate. Journal of the American Chemical Society 124 (44):13271-13281.

21. Stavrov SS, Wright WW, Vanderkooi JM, Fidy J, Kaposi AD (2002) Optical and IR absorption as probe of dynamics of heme proteins. Biopolymers 67 (4-5):255-258.

22. Kaposi AD, Vanderkooi JM, Wright WW, Fidy J, Stavrov SS (2001) Influence of static and dynamic disorder on the visible and infrared absorption spectra of carbonmonoxy horseradish peroxidase. Biophysical Journal 81 (6):3472-3482.

23. Kaposi AD, Vanderkooi JM, Stavrov SS (2006) Infrared Absorption Study of the Heme Pocket Dynamics of Carbonmonoxyheme Proteins. Biophysical Journal 91 (11):4191-4200.

24. Stavrov SS (2010) Shape of the carbon monoxide infrared absorption band of carboxyheme proteins as a probe of the protein anharmonicity. Spectr-Int J 24 (3-4):409-415.

25. Eicher H, Bade D, Parak F (1976) Theoretical determination of the electronic structure and the spatial arrangement of ferrous iron in deoxygenated sperm whale myoglobin and human hemoglobin from Mossbauer experiments. J Chem Phys 64 (4):1446-1455.

26. Herta C, Winkler H, Benda R, Haas M, Trautwein AX (2002) Dynamic structural disorder of the $\mathrm{FeO} 2$ moiety in oxymyoglobin studied by nuclear resonant forward scattering of synchrotron radiation. Eur Biophys J 31 (6):478-484.

27. Trautwein AX, Bill E, Bominaar EL, Winkler H (1991) Iron-Containing Proteins and Related Analogs - Complementary Mossbauer, Epr and Magnetic-Susceptibility Studies. Struct Bond 78:1-95. 28. Gonser U, Maeda Y, Trautwein A, Parak F, Formanek H (1974) Sign and orientation determination of the principial axis of the electric field gradient in $\mathrm{Fe}^{57}$ enriched deoxygenated myoglobin single crystals. Z Naturforsch 29b:241-244.

29. Oshtrakh MI (2004) Mossbauer spectroscopy in biomedical research. Faraday Discussions 126:119-140. 
30. Oshtrakh MI, Semionkin VA (2004) The features of Mossbauer spectra of hemoglobins: Approximation by superposition of quadrupole doublets or by quadrupole splitting distribution? Hyperfine Interact 159 (1-4):345-350.

31. Parak F, Heidemeier J, Nienhaus GU (1988) Protein Structural Dynamics as Determined by Mossbauer- Spectroscopy. Hyperfine Interact 40 (1-4):147-157.

32. Croci S, Ortalli I (2011) Mossbauer Absorption Spectroscopy: Bio-medical applications. Riv Nuovo Cimento 34 (2):69-101.

33. Sanders LK, Arnold WD, Oldfield E (2001) NMR, IR, Mossbauer and quantum chemical investigations of metalloporphyrins and metalloproteins. J Porphyr Phthalocyanines 5 (3):323-333.

34. Pápai M, Vankó G (2013) On Predicting Mössbauer Parameters of Iron-Containing Molecules with Density-Functional Theory. Journal of Chemical Theory and Computation 9 (11):5004-5020.

35. M. J. Frisch, G. W. Trucks, H. B. Schlegel, G. E. Scuseria, M. A. Robb, J. R. Cheeseman, J. A. Montgomery J, T. Vreven, K. N. Kudin, J. C. Burant, J. M. Millam, S. S. Iyengar, J. Tomasi, V. Barone, B. Mennucci, M. Cossi, G. Scalmani, N. Rega, G. A. Petersson, H. Nakatsuji, M. Hada, M. Ehara, K. Toyota, R. Fukuda, J. Hasegawa, M. Ishida, T. Nakajima, Y. Honda, O. Kitao, H. Nakai, M. Klene, X. Li, J. E. Knox, H. P. Hratchian, J. B. Cross, V. Bakken, C. Adamo, J. Jaramillo, R. Gomperts, R. E. Stratmann, O. Yazyev, A. J. Austin, R. Cammi, C. Pomelli, J. W. Ochterski, P. Y. Ayala, K. Morokuma, G. A. Voth, P. Salvador, J. J. Dannenberg, V. G. Zakrzewski, S. Dapprich, A. D. Daniels, M. C. Strain, O. Farkas, D. K. Malick, A. D. Rabuck, K. Raghavachari, J. B. Foresman, J. V. Ortiz, Q. Cui, A. G. Baboul, S. Clifford, J. Cioslowski, B. B. Stefanov, G. Liu, A. Liashenko, P. Piskorz, I. Komaromi, R. L. Martin, D. J. Fox, T. Keith, M. A. Al-Laham, C. Y. Peng, A. Nanayakkara, M. Challacombe, P. M. W. Gill, B. Johnson, W. Chen, M. W. Wong, C. Gonzalez, Pople JA (2004) Gaussian 03, Revision D.01. Revision D. 01 edn. Gaussian, Inc., Wallingford CT.

36. Kaposi AD, Wright WW, Fidy J, Stavrov SS, Vanderkooi JM, Rasnik I (2001) Carbonmonoxy horseradish peroxidase as a function of $\mathrm{pH}$ and substrate: Influence of local electric fields on the optical and infrared spectra. Biochemistry 40 (12):3483-3491. 
37. Park SY, Yokoyama T, Shibayama N, Shiro Y, Tame JRH (2006) 1.25 angstrom resolution crystal structures of human haemoglobin in the oxy, deoxy and carbonmonoxy forms. J Mol Biol 360 (3):690701.

38. Kachalova GS, Popov AN, Bartunik HD (1999) A steric mechanism for inhibition of CO binding to heme proteins. Science 284 (5413):473-476.

39. Debrunner PG (1989) Mossbauer spectroscopy of iron porphyrins. In: Lever ABP, Gray HB (eds) Iron Porphyrins, vol 3. Iron Porphyrins. VCH Publishers, New York, pp 139-234. 